\title{
Response of Saccoglossus kowalevskii (Phylum Hemichordata, Class Enteropneusta) to changes in diet
}

\author{
Douglas C. Miller \\ Graduate College of Marine Studies, University of Delaware, Lewes, Delaware 19958-1298, USA
}

\begin{abstract}
Hypotheses concerning the response of deposit feeders to changes in diet were tested in laboratory experiments using Saccoglossus kowalevskii (Phylum Hemichordata, Class Enteropneusta) from Cape Henlopen, Delaware, USA. The initial hypothesis was that a step change in sediment available for consumption would cause a rapid change in feeding rate. This was rejected since experiments consistently demonstrated a delay in the response of ca $1 \mathrm{~h}$, similar to the gut throughput time of this organism. Additional measurements verified this result and showed that change in feeding rate can occur slowly. This pattern is not an artifact of sampling design nor a result of aggregating responses of differing individuals. Hypothetical mechanisms for the delayed and gradual response were tested using predicted relative rates of change of increasing and decreasing feeding rate. A hypothesis based on optimal foraging considerations was the most consistent with the result that an increase in feeding rate occurs more quickly than a decrease. Overall, the results of these experiments suggest that feeding rate responses are gradual and variable. This contrasts with the visually observed, immediate and stereotyped behavioral responses of deposit feeders to flow and sediment transport. This delay represents a temporary decoupling of sediment dynamics and feeding on a time scale of minutes to hours. Further, because of the delayed response, the simple marker method for measuring ingestion rate in surface deposit feeders may yield reliable results even if marker material is applied in large quantities.
\end{abstract}

\section{INTRODUCTION}

Behavioral responses of benthic microphagous organisms have been investigated in a wide variety of flow and sediment dynamic environments. In unidirectional, steady flows (e.g. Nowell et al. 1989, Levinton 1991) organisms respond quickly to changes in experimentally imposed flow conditions and particle flux in the orientation of food capturing appendages and in feeding mode. Similarly, in wave-generated oscillatory flows, organisms can alter feeding mode quickly and even change feeding appendage orientation on the time scale of seconds of the wave (Trager et al. 1990, Turner \& Miller 1991a, b. Miller et al. in press). Such responses have been explained in terms of their supposed adaptive advantage resulting from increased capture rate, particle availability or nutritional quality content (Shimeta \& Jumars 1991, Taghon \& Greene in press). Implicit in this adaptive argument is the assumption that the digestive machinery of the alimentary tract can and does change accordingly. The most easily observed and measured gut kinetic parameters, the throughput rate (here, egestion rate) and throughput time, thus should show rapid responses to changes in feeding behavior and diet.

To investigate this assertion, I conducted several experiments with the surface deposit-feeding acorn worm Saccoglossus kowalevskii (A. Agassiz 1873) (Phylum Hemichordata, Class Enteropneusta, Family Harrimaniidae). This species is a sedentary deposit feeder common on intertidal mud-and sandflats on the eastern coast of North America and on the Atlantic coast of Europe (Hyman 1959). S. kowalevskii lives in the sediment in a U-shaped burrow with separate feeding pits and points of defecation of conical coils of fecal material. Feeding individuals use a highly muscular and ciliated proboscis to probe the sediment surface near the burrow opening (see also Knight-Jones 1953). Repeated probing results in the characteristic surface trace, aptly named a 'feeding rosette' (Ruppert \& Fox 1988). Sediment particles may be moved by ciliary action along the proboscis to the mouth in the collar 
region, or sediment aggregates adhering to the proboscis may be withdrawn with it into the burrow where they are ingested. S. kowalevskii feeds unselectively on medium to large sand-sized particles (260 to 1070 um; Brandon 1991; see also Knight-Jones 1953, Dobbys \& Guckert 1988, Carey \& Mayer 1990).

Saccoglossus kowalevskil feeds primarily at the dynamic sediment-water interface. As suggested by the absence of dark, reduced sediment in the feces, subsurface feeding occurs infrequently in our laboratory and at Cape Henlopen, Delaware, USA. While the animal can readily change feeding pits and points of defecation, observations in the laboratory suggest that movement is infrequent as the locations of pits and piles remain unmoved for days or weeks. Surficial sediments at Cape Henlopen consist of medium sand and are subjected to moderate wind wave energy from north-western exposure (Ray 1989, M. J. Bock unpubl.). Wave energy generates vortex ripples on the sand surface and frequently obliterates evidence of biological activity (feeding rosettes, defecation, and tracking) by infaunal and epifaunal organisms (for typical species, see Maurer \& Aprill 1979, Bianchi 1988). These observations and wave and sediment transport rate measurements (M. J. Bock unpubl., A. J. Ray \& Miller unpubl.) reveal a sediment dynamical environment similar to that at False Bay, Washington, USA, described by Miller \& Sternberg (1988). Thus, one should expect that a sedentary surface deposit feeder in such an intertidal environment should be subject to rapid changes in sediment and food resources available to it.

Miller et al. (in press) observed a rapid change in feeding behavior of Saccoglossus kowalevskii in oscillatory flows that transport sediment particles. In low flows, the proboscis remains exposed and relatively immobile near the burrow opening. In high flow and sediment flux, the proboscis is completely withdrawn into the opening, which traps particles in near-bed transport. As compared to feces produced in still water, feces produced following active sediment transport were darker in appearance and composed of finer material. When flow was stopped, the worms quickly returned to the 'still-water' feeding mode with the proboscis extending several $\mathrm{cm}$ from the burrow opening, eventually creating the frequently observed feeding rosette. The withdrawal response of the feeding appendage to flow is not unique. Levinton (1991) describes a similar response of the feeding siphon of several species of the bivalve genus Macoma.

Although feeding behavior and rate are of intrinsic interest to studies of deposit-feeding, they are relevant to other benthic oceanographic processes as well. From a geochemical perspective, it is the rate of sediment processing or bioturbation that in large part controls the vertical profile of sedimentary organic matter (e.g. Mayer \& Rice 1992), including those components known to influence feeding rate (Taghon \& Greene 1990). Besides advecting and mixing sediments, deposit feeders process sediment through a chemical reactor (its digestive systemi Penry \& Jumars 1987 . 1990, Penry 1989) that can substantially alter sedimentary components (Carey \& Mayer 1990). Thus those parameters of interest to biologists are also important to geochemists. Accordingly, rate measurements made for one purpose thus may have broader significance.

Saccoglossus kowalevskii has several advantages for my experiments. They are well-studied, large, surface deposit feeders that actively explore the surficial sediments in their feeding area (e.g. Carey 1989, Carey \& Farrington 1989, Carey \& Mayer 1990). They have a separate feeding pit and point of defecation, process prodigious amounts of sediment in a short amount of time (e.g. 100's $\mathrm{mg} \mathrm{h}^{-1}$ ) and produce easily collected feces. Consequently, it is straightforward to impose experimental changes in available food resources and measure the egestion rate response gravimetrically. Passage of material through the gut is in 'plug flow' (Penry \& Jumars 1987, Carey 1989) so the gut throughput time can be readily measured by noting the time from application to egestion of some visibly distinct food tracer. They are easy to maintain, grow and reproduce in the laboratory (Brandon 1991). I conducted a series of laboratory experiments in which sedimentary diet changed in step fashion, a highly simplified and artificial mimic of changes in food availability thought to occur in the field. These experiments were designed to test predictions of hypotheses concerning the egestion rate response to this abrupt diet change. The specific hypothetical mechanisms will be described in detail and evaluated in the 'Discussion'.

\section{METHODS}

General procedures. Saccoglossus kowalevskii was collected from the intertidal sandflats at Cape Henlopen $\left(38^{\circ} 47^{\prime} \mathrm{N}, 75^{\circ} 06^{\prime} \mathrm{W}\right.$ ) in July 1987 and February 1988. Worms (ca $10 \mathrm{~cm}$ in apparent length) were carefully dug from the sediment and immediately placed in plastic freezer containers $(10 \times 10 \times 13 \mathrm{~cm}$ deep) of $1 \mathrm{~mm}$ sieved, macrofauna-free sand from the collection site. This sediment is a moderately sorted, medium sand with a median grain size of $240 \mathrm{~mm}$ and $<1 \%$ siltclay by weight (Ray 1989). Worms and containers were transported to seawater tables in the Cannon Marine Laboratory where they were held for experiments. Details of the care and maintenance of these organisms and their environmental conditions will be described elsewhere (Miller unpubl.). Animals were uniquely 
designated by a Roman letter (A to $\mathrm{V}$ ) and in certain cases a numerical subscript. Some containers contained more than 1 worm (worms D and $D_{2}, F_{1}$ and $F_{2}, K$ and $L, S$ and $S_{2}, T$ and $U$, and 3 in one case: $O, P$ and $R$ ), but by position and diameter of the fecal string it was always possible to determine each worm's identity I have never observed any manner of aggressive behavior or interference between worms in a container. Thus for purposes of statistical analysis, I assumed that each worm's feeding behavior can be treated as independent from its neighbors' (see also Miller unpubl.). For convenience of the investigator, I arranged the containers in rows near the edge of the upstream third of the seawater table.

To measure egestion rate, I collected and weighed fecal material egested in a known amount of time. Saccoglossus kowalevskii produces a characteristic conical coil of string-like fecal castings, which is easily and quantitatively removed by a $7.5 \mathrm{ml}$ bulb transfer pipet. I placed fecal material in tared plastic dishes and removed excess seawater with the pipet. I obtained wet weights to $1 \mathrm{mg}$ of the fecal material and dried the samples in an oven at 45 to $60^{\circ} \mathrm{C}$ for at least $1 \mathrm{~d}$. Pretests showed that stable dry weights were obtained in a minimum of $12 \mathrm{~h}$ of drying. Tare, wet und dry weights of the samples were used to calculate the contained sediment weight by correcting for salt content via an empirically determined adjustment factor of about $4 \%$ of the water weight. A simple propagation of errors analysis suggested that sample weights were thus determined with a precision of $\leq 5 \mathrm{mg}$ for a typical $500 \mathrm{mg}$ sample.

To begin each experiment, worms were dusted with a thin ( $\leq 4 \mathrm{~mm}$ thick) layer of 'fresh sediment', that is, $1 \mathrm{~mm}$ sieved sediment recently collected at Cape Henlopen and held in the separate, macrofauna-free containers in the seawater table. Though I did not analyze subsamples of this sediment, typical values from Cape Henlopen in March 1992 are: $5 \mu \mathrm{g} \mathrm{g}^{-1}$ chlorophyll a (see also Ray 1989, Brandon 1991), $0.4 \mathrm{mg} \mathrm{g}^{-1}$ protein (by the method of Mayer et al. 1986, M. J. Bock unpubl.), and $0.36 \%$ organic matter by loss on ignition at $450^{\circ} \mathrm{C}$ (M. J. Bock unpubl.). During the experiments, I adjusted the mixture of cold and hot water entering the seawater table to maintain temperature as constant as possible, usually to within a few tenths of a degree Centigrade. Temperature was measured with a digital thermometer when applying sediment treatments or taking fecal samples. At the same time, salinity was measured with a digital conductivity meter. The seawater table was illuminated continuously by fluorescent lights yielding $5 \times 10^{14}$ quanta $\mathrm{s}^{-1} \mathrm{~cm}^{-2}$, about $1 \%$ of full sunlight (Brandon 1991).

Fecal material experiment. I measured the response of Saccoglossus kowalevskii to their fecal material in the following experiment conducted in March 1989 Thirteen worms were allowed to feed on fresh sediment for $4 \mathrm{~h}$. Fecal material was collected and weighed wet for all individuals. For 5 randomly chosen individuals ( $F, G, I, M$ and $Q$ ), I placed their own disaggregated feces in their feeding pit. The remaining $8(A, C, D, K$, $L, O, P$ and $R$ ) received fresh sediment in wet weight equal to their fecal production over the previous $4 \mathrm{~h}$. Egestion rate was measured as described above for the next $4 \mathrm{~h}$. On the following day, I employed the same procedure except that those having previously received fresh sediment received their fecal material and vice versa. Seawater temperature over the experiment ranged from 18.9 to $19.1^{\circ} \mathrm{C}$; salinity ranged from 33.0 to 33.5 psu. I analyzed the salt-corrected dry sediment weights separately for each hour following the application of fresh sand or feces. Data for each hour were analyzed as a separate, 3-way analysis of variance (ANOVA) with worm and day employed as blocking factors to increase power for the treatment (i.e. fresh sediment vs feces) effect test (Zar 1984). Preliminary analysis using log-transformed data and a multiplicative model led to identical statistical conclusions in tests of interest. For simplicity of analysis and interpretation, all subsequent analyses were conducted with untransformed data and an additive model. All statistical hypotheses were evaluated using the conventional Type I (or ' $\alpha$ ') error rate of 0.05 .

Glass bead experiment. I conducted this experiment to test the hypothesis that the response to a step change in diet is delayed and gradual rather than immediate. In April 1989, I measured egestion hourly for $8 \mathrm{~h}$ for the same population of 13 worms used in the fecal material experiment. I then applied glass beads to fill each of their feeding pits. These beads were 177 to $257 \mu \mathrm{m}$ in diameter (Cataphote, Inc., soda-lime glass microbeads, density 2.42 to $2.50 \mathrm{~g} \mathrm{~cm}^{-3}$ ) and were washed twice with $3 \% \mathrm{H}_{2} \mathrm{O}_{2}$ and 4 times with seawater before application. I measured egestion hourly for $8 \mathrm{~h}$ thereafter. Seawater temperature over the experiment ranged from 22.0 to $22.2^{\circ} \mathrm{C}$; salinity ranged from 33.3 to 33.6 psu. Statistical analysis for changes in egestion rate was by repeated-measures ANOVA with worms as subjects and measurements of egesta repeated by hour (Winer 1971, Kirk 1982). A test for trends among the means (Kirk 1982) following glass bead application was used to describe and quantify the response. For comparison with the fresh sediment, samples of glass beads were found to have $\leq 0.2 \mu \mathrm{g} \mathrm{g}^{-1}$ chlorophyll $a$ and no detectable phaeopigments by the standard spectrophotometric assay (Brandon 1991), no detectable protein (Mayer et al. 1986) and only $0.01 \%$ loss on ignition. Thus the beads were presumed to have essentially no nutritive value to Saccoglossus kowalevskii (see Taghon \& Greene 1990) 
Reciprocal experiment. I conducted this experiment in March 1990 to test the hypothesis that feeding would increase and decrease at the same absolute rate. Egestion rate was measured for $4 \mathrm{~h}$ for a population of 18 worms (the 13 used above plus 5 additional). As in the glass bead experiment, I applied beads to the feeding pits and measured egestion rate for the next $6 \mathrm{~h}$ and for a $14 \mathrm{~h}$ long overnight period. The next day, I reapplied glass beads, measured egestion for $4 \mathrm{~h}$, and then applied fresh sand. I again measured the egestion rate response for the next $6 \mathrm{~h}$ and for a $14 \mathrm{~h}$ long overnight period. Seawater temperature over the experiment ranged from 16.5 to $16.9^{\circ} \mathrm{C}$ for the first day, 16.7 to $16.8^{\circ} \mathrm{C}$ for the second day. Salinity ranged from 32.3 to 33.6 psu. As above, statistical analysis for change in egestion rate over time was by repeated-measures ANOVA with worms as subjects (Winer 1971, Kirk 1982). Tests for trends among the means (Kirk 1982) following glass bead or sediment application were used to describe and quantify the responses. I used a $t$-test to assess differences in magnitude of the slope of these linear trends between the glass-bead and sand treatments.

\section{RESULTS}

\section{Response to fecal material}

I analyzed these data as 4 three-way ANOVAs, one for each hour after application, in which worm and day were employed as blocking factors. Egestion rate means and ANOVA test results are depicted in Fig. 1 and Table 1. The first pair of data in the figure represents the amount of material egested in the hour following application of the feces or fresh sediment. If egestion rate did decrease immediately in response to the treatment, then egestion measurements for this hour would be lowered and this would be reflected in a treatment difference. No significant difference was found, in fact, the mean for the fresh sediment treatment was slightly lower. The application of fecal material did cause a decrease in mean egestion rate, but not until the second hour following application (Fig. 1, Table 1). The treatment differences increased in the next 2 hours, being highly significant in the third, but non-significant in the fourth (Table 1). The lack of statistical significance in all tests in the fourth hour appears due to an increased variability exhibited by the fresh sediment group that resulted in a 2-fold increase in the ANOVA error mean square term as compared to other hours. Taken over all hours, the application of feces resulted in a $20 \%$ decrease in mean feeding rate. The maximum difference between treatments was $32 \%$ at $+3 \mathrm{~h}$. Among worm differences (or worm effects) were expected and were statistically significant in the first 3 hours (Table 1). If not for the increased error term in the fourth hour, worm effect here too would have been judged significant (though results of such blocks tests

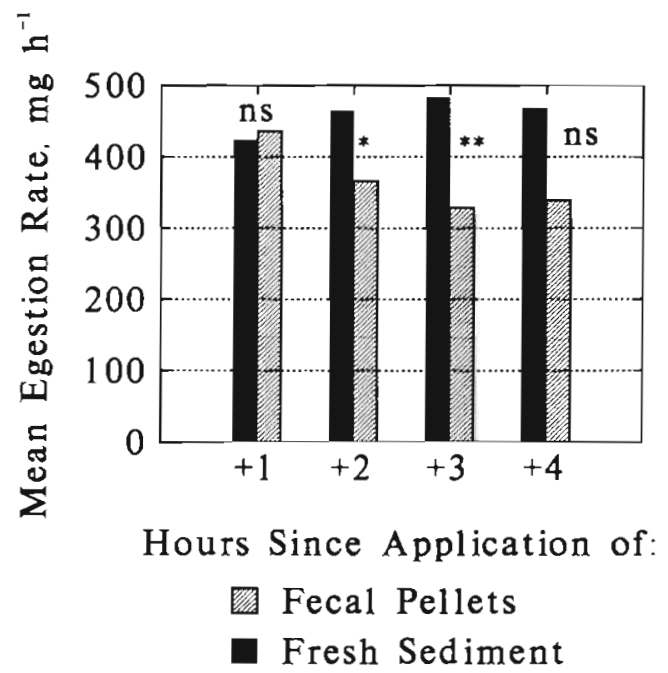

Fig. 1. Saccoglossus kowalevskii. Mean feeding rate of worms ( $\mathrm{n}=13$ ) fed fresh sediment (solid bars) and fecal material (hatched bars) by hour following application. ns: not significantly different, $p>0.05$; ${ }^{\prime}$ significantly different at $p \leq 0.05$; $\cdots p \leq 0.01$, by ANOVA analysis in Table 1

Table 1. Saccoglossus kowalevskii. Probability values for ANOVA F-test of individual worm, day of experiment and sediment treatrnent effects in the fecal material experiment. Results for each hour since sediment treatment are those of a separate 3-way, unreplicated factorial ANOVA. Means for the sediment treatment tests are shown in Fig. 1. The applicable error-mean-square (11 d.f.) was used to test for each of the effects, and no interaction terms were included in the 4 identical ANOVA models

\begin{tabular}{|c|c|c|c|c|c|}
\hline \multirow[t]{2}{*}{ Source of variation } & \multirow[t]{2}{*}{ d.f. } & \multicolumn{4}{|c|}{ ANOVA probabilities for hour since sediment treatment } \\
\hline & & $+1 \mathrm{~h}$ & $+2 \mathrm{~h}$ & $+3 h$ & $+4 \mathrm{~h}$ \\
\hline Individual worm & 12 & 0.027 & 0.005 & 0.008 & 0.11 \\
\hline Day of experiment & 1 & 0022 & 0.003 & 0.21 & 0.41 \\
\hline Sediment treatment & 1 & 0.70 & 0.013 & 0.007 & 0.17 \\
\hline Error & 11 & & & & \\
\hline
\end{tabular}


may sometimes be unreliable due to restriction error; Montgomery 1984). Day effects were significant for the first 2 hours, but not for the last 2 hours. Initial differences are not due to a difference between the randomly selected worm groups (of $n=5$ and $n=8$ ), since mean egestion rates for the fresh sediment and fecal material groups differed in the first hour by only $5 \%$ (451 vs $429 \mathrm{mg} \mathrm{h} \mathrm{h}^{-1}$ ). The initial day differences are presumably due to some unknown difference in the initial conditions of the experiment, perhaps food quality, though this unresolved effect appears to be mitigated by the (covarying) treatment (fecal matter) or hour effects of the experiment. Variations in temperature and salinity were small and cannot account for the changes or patterns in egestion rate observed.

A

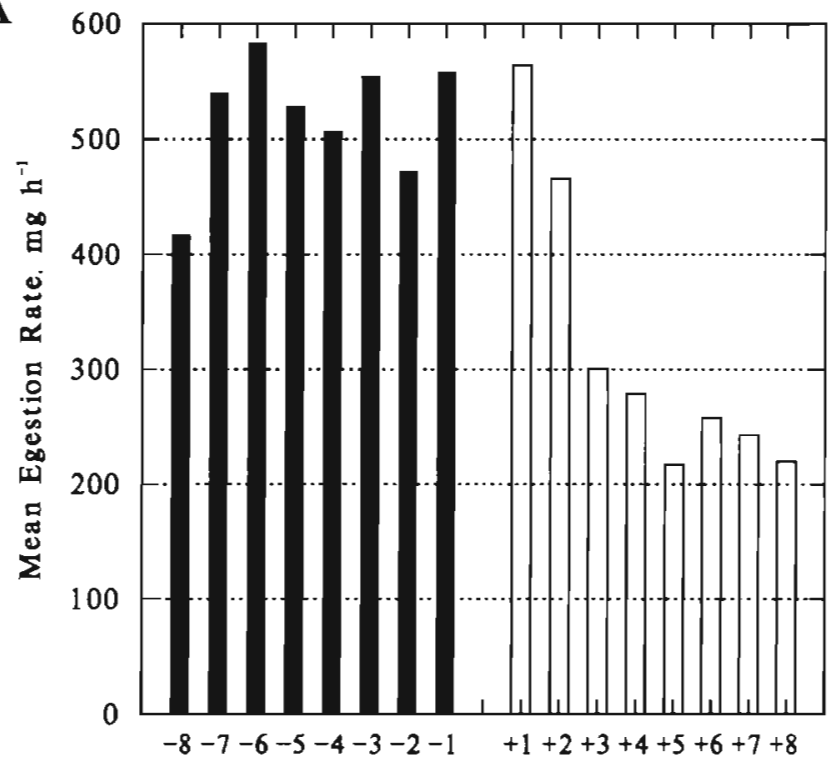

Hours To (-) or Since (+) Application of Beads ( $\square$ )

\section{Response to glass beads}

Results from this experiment are shown in Fig. 2 and Table 2. For the 8 hours following application of beads, the repeated-measures ANOVA analysis confirmed the large temporal differences seen in mean values in Fig. 2A (open bars) as statistically significant (treatment or hours effects, $p<0.001$, Table 2). There was no decrease seen in the first hour after application, a result consistent with that of the previous experiment and the delayed-response hypothesis. Egestion rate means decreased in the second through the fourth hours, then remained relatively constant. Tests for trends among these means revealed a significant linear trend (Table 2) with marginal evidence for higher-order, non-linear trends. A test for a quadratic trend was also
B
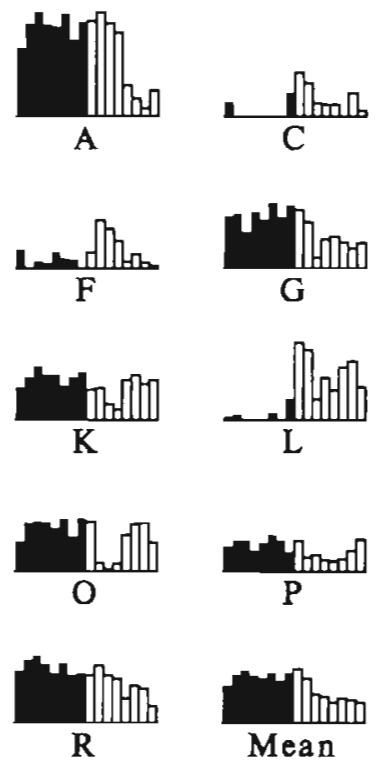
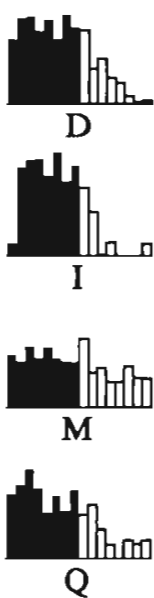

Sediment

Beads

Fig. 2. Saccoglossus kowalevskii. Results of glass bead experiment. (A) Mean feeding rate of worms ( $\mathrm{n}=13$ ) fed fresh sediment (solid bars) followed by glass beads (open bars). (B) Feeding rate of individual worms (Roman letters) fed fresh sediment (solid bars) followed by glass beads (open bars). For scale, mean egestion rates from (A) are shown in the last plot

Table 2. Saccoglossus kowalevskii. Repeated-measures ANOVA table for the glass bead experiment. Results are from a repeated measures design with individual worms used as blocks. The conventional tests use the error mean square [84 d.f.; value: 30085 $\left.\left(\mathrm{mg} \mathrm{h}^{-1}\right)^{2}\right]$ for each of the effects and trends test

\begin{tabular}{|lrcc|}
\hline Source of variation & d.f. & F-Ratio & Probability \\
\hline Among subjects (individual worms) & 12 & 4.28 & $<0.001$ \\
Within subjects & 91 & 7.03 & $<0.001$ \\
Treatment (hour after application) & 7 & 35.7 & $<0.001$ \\
Linear trend & 1 & 2.26 & 0.045 \\
Departure from linear trend & 6 & 10.8 & 0.0014 \\
Quadratic trend & 1 & 0.55 & 0.74 \\
Higher order trends & 5 & & \\
Error & 84 & & \\
Total & 103 & & \\
\hline
\end{tabular}


highly significant, and there was no evidence for higher-order trends remaining. Thus the response appears to be gradual in addition to being delayed. The decrease in mean feeding rate to ca $50 \%$ of preapplication values persists for at least $8 \mathrm{~h}$.

Fig. 2B shows the time course of egestion rate for each worm (designated by Roman letters) and shows variability among worms as well as over time. Few if any worms show abrupt decreases in egestion rate following application of beads. The delayed and gradual mean egestion rate response appears to reflect that exhibited by the individual worms. However, a relatively gradual aggregate, population-mean curve could result from combining individuals differing in delay or slope. Standard statistical trend tests lack sufficient power for sequences as short as only 8 time intervals. Alternatively, I counted for each hour the number of worms showing decreased egestion rate compared to that immediately before $(-1$ h) application of beads. For the 13 worms, these 8 hourly counts were $8,8,12,11,11,11,11$, and 10 respectively. In the first $2 \mathrm{~h}$, there is no statistical evidence of a decrease ( $p=0.29$, 1-tailed binomial test). At all following hours, there is evidence for a decrease $(p=0.002,0.011$ and 0.046 for 12,11 and 10 worms respectively). This is the temporal pattern in counts expected if the response was both delayed, gradual and relatively homogeneous over the experimental population of worms. The above tests are conservative since they include 3 worms (C, F and $L$ ) having very low egestion rates before the application of beads. Worm F did not defecate in the period preceding beads and thus could not show a decreased rate response as measured above. Based on the analysis, I conclude that the delayed and gradual decrease in means (Fig. 2A, Table 2) is not an artifact of sampling frequency or of pooling results of individual with heterogeneous responses in egestion rate.

Because of their plug-flow gut and the clear difference in appearance between sand and glass beads, it was possible (Carey 1989) to note the time of first appearance of beads in the feces and to use this as a measure of gut throughput time. These values ranged from 29 to $78 \mathrm{~min}$ with a median of $49 \mathrm{~min}$ for these 13 worms at $22^{\circ} \mathrm{C}$. The first appreciable decrease in egestion rate (second hour, denoted $+2 \mathrm{~h}$ in Fig. 2A) was thus seen about 1 throughput time after application.

For comparative purposes, I conducted a similar ANOVA analysis of the 8 hours of data before application of beads. The mean egestion rate was $520 \mathrm{mg}$ $\mathrm{h}^{-1}$ (similar to those in the first experiment) with a range of about 50 to $1000 \mathrm{mg} \mathrm{h}^{-1}$ for means for each of the 13 worms. ANOVA tests revealed a marginally significant time effect ( $\mathrm{p}=0.023$ ); Tukey's 'honestly significant difference test' (Zar 1984) detected only 1 difference, specifically, between the lowest and highest mean values $(-8 \mathrm{~h}$ and $-6 \mathrm{~h}$; Fig. 2A). Possible reasons for this difference will be discussed below. Since temperature and salinity varied little over the 16 total hours of this experiment, they cannot account for the changes in egestion rate observed.

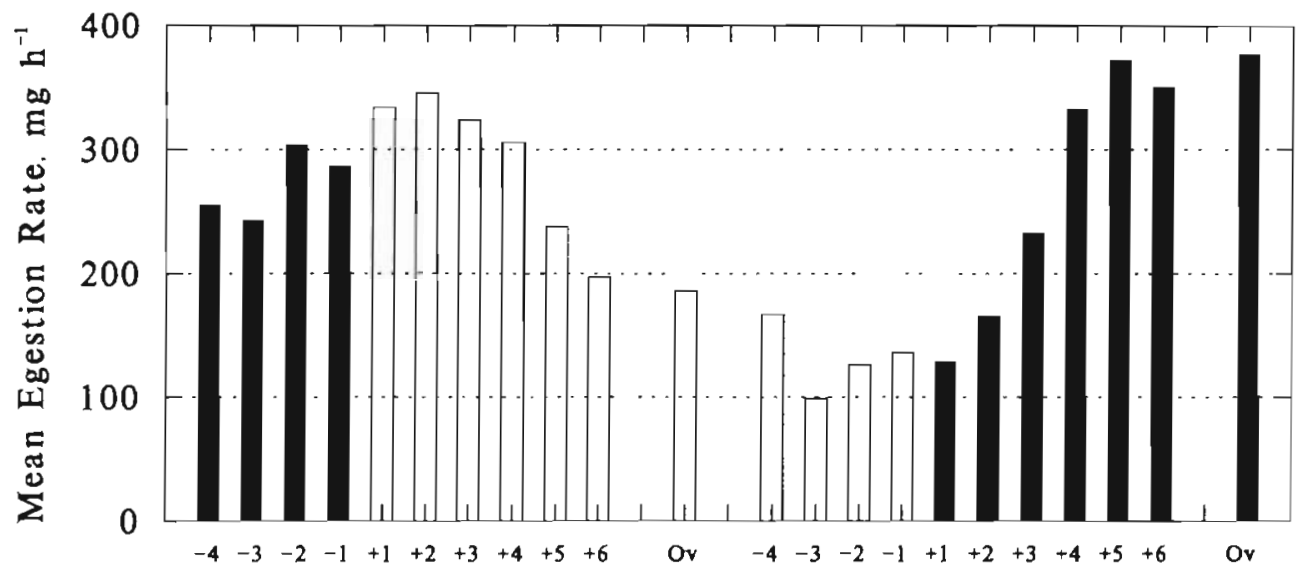

Hours To $(-)$ or Since (+) Application of Beads $(\square)$ or Sediment ( $(\mathbf{)})$

Fig. 3. Saccoglossus kowalevskii. Results of reciprocal experiment. Mean feeding rate of worms ( $\mathrm{n}=18$ ) on fresh sediment (solid bars, left side) followed by glass beads (open bars, middle) and returned to fresh sediment (solid bars, right). This experiment was conducted on 2 days in two $10 \mathrm{~h}$ periods denoted -4 to $+6 \mathrm{~h}$. Ov: feeding rate for $14 \mathrm{~h}$ overnight period 
Table 3. Saccoglossus kowalevskii. Repeated-measures ANOVA results for the reciprocal experiment. Results are from 2 repeated measures design ANOVAs with individual worms used as blocks. The applicable, conventional error mean squares [85 d.f.; values: 21800 and $18965\left(\mathrm{mg} \mathrm{h}^{-1}\right)^{2}$ for glass beads and fresh sediment respectively] were used to test for each of the effects and trends and to estimate slope SE for comparison of magnitudes

\begin{tabular}{|c|c|c|c|c|c|}
\hline \multirow[t]{2}{*}{$\begin{array}{l}\text { a. ANOVA tables } \\
\text { Source of variation }\end{array}$} & \multirow[t]{2}{*}{ d.f. } & \multicolumn{2}{|c|}{ On glass beads } & \multicolumn{2}{|c|}{ On fresh sediment } \\
\hline & & F-Ratio & Probability & F-Ratio & Probability \\
\hline Among subjects (individual worm) & 17 & 9.56 & $<0.001$ & 17.2 & $<0.001$ \\
\hline Within subjects & 90 & & & & \\
\hline Hour after application & 5 & 2.96 & 0.016 & 10.0 & $<0.001$ \\
\hline Linear trend & 1 & 12.5 & $<0.001$ & 45.4 & $<0.001$ \\
\hline Error & 85 & & & & \\
\hline \multirow[t]{2}{*}{ b. Comparison of slopes } & & \multicolumn{2}{|c|}{ On glass beads } & \multicolumn{2}{|c|}{ On fresh sediment } \\
\hline & & Mean & SE & Mean & $\mathrm{SE}$ \\
\hline Slope value, (mg dry sediment $h^{-1}$ ) $h^{-1}$ & & $(-) 29.4$ & 8.32 & $(+) 52.3$ & 7.76 \\
\hline$t$-test of magnitude & & \multicolumn{4}{|c|}{$t=2.01,2$-tailed $\mathrm{p}=0.046$ (with $170 \mathrm{~d}$ f.) } \\
\hline
\end{tabular}

\section{Response to glass beads and fresh sediment}

Egestion rates over this 2-day experiment are shown in Fig. 3 and Table 3. Among the 6 hours following application of both glass beads (Day 1) and fresh sediment (Day 2), differences in mean egestion rate are highly significant (Table 3 hour effects; $p=0.016$ for Day 1, $\mathrm{p}<0.001$ for Day 2). F-tests for linear trends are highly significant ( $\mathrm{p} \leq 0.001$ ) for both responses. Over the $6 \mathrm{~h}$ period on glass beads, egestion rates fell at an average rate of $(-) 29\left(\mathrm{mg}\right.$ dry sediment $\left.h^{-1}\right) h^{-1}$. Over the comparable period on fresh sediment, egestion rates rose $52\left(\mathrm{mg}\right.$ dry sediment $\mathrm{h}^{-1}$ ) $\mathrm{h}^{-1}$, a rate $78 \%$ greater in magnitude. A t-test of slope magnitudes only (i.e. ignoring the sign) revealed that the rise was marginally more rapid than fall $(t=2.01, p=0.046$, using the most powerful test possible; Table 3 ). Probability values are 2-tailed because deviations in either direction were possible under the hypotheses entertained below.

Gut throughput time, measured as first appearance of newly provided food material in the feces, was 70 min (median of 18 worms) for the fall in egestion rate on glass beads and 214 min (median) for the rise on fresh sediment (Fig. 4A). Pairing throughput times by worm, the nonparametric Friedman's test (Zar 1984) indicated that these treatment differences are significant at $\mathrm{p}=0.018$. Not only is the median time longer when switching from beads to sand (i.e. increasing feeding rate), but greater variability is also seen. These data include those of 2 worms ( $M$ and $Q$ ) that did not egest sand in the $6 \mathrm{~h}$ following application on the second day of the experiment (i.e. their gut throughput time was longer than $6 \mathrm{~h}$ ). For this reason, the upper limit on this box plot is the largest measured value of the remaining 16 worms. Since only ranks are required for the Friedman's test, I was able to include all 18
A

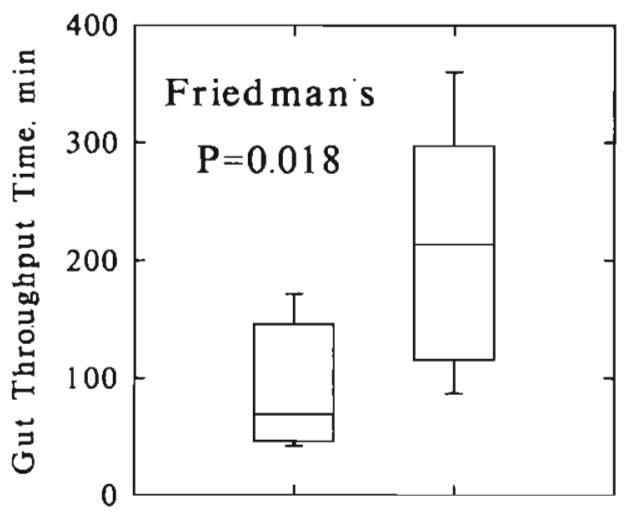

B

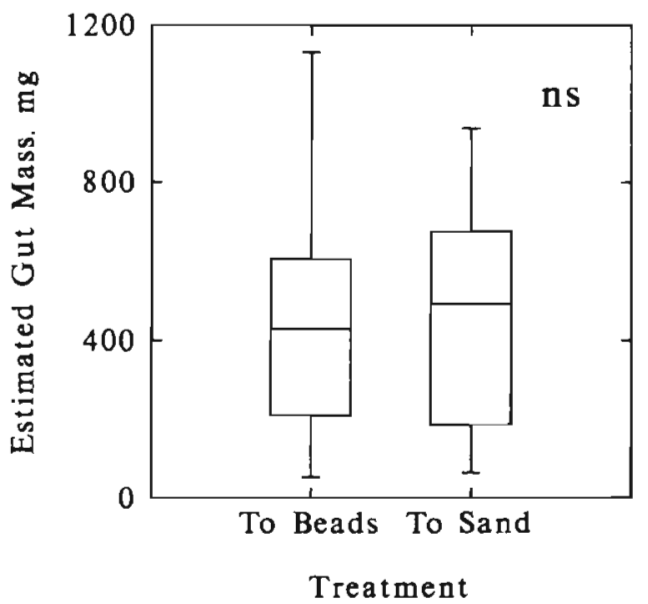

Fig. 4. Saccoglossus kowalevskii. Results from reciprocal experiment depicted as box plots, showing range (thin lines) 25th and 75th percentiles (bottom and top of box) and the median (line across box) values. (A) Box plots of gut throughput times for 18 worms for the sand-to-beads and beads-tosand transitions, or first and second days respectively, of the experiment depicted in Fig. 3. (B) Box plots of estimated masses of material in gut for 16 worms. See text for details of calculation and analysis procedure 
worms' data in the test. Fig. 4B shows the estimated mass of material in the gut at the time of application of beads or sand. The mass of material egested before the appearance of demarcation between sand and beads was not directly measured, but it can be estimated as follows. For each worm, this mass is at a minimum the sum of the weights for all feces sampled in the hours before that in which the bead-sediment demarcation appeared. For this final hour, I prorated the sampled mass of feces (i.e. that sampled at the end of the hour, consisting of sand and beads) by the time of appearance within the hour. For example, if the demarcation was seen 40 min into the hour, then two-thirds of the mass of egesta for that last hour was added to the lower-bound sum. I made this calculation for those 16 worms that did egest the marker within $6 \mathrm{~h}$ on both days (if no demarcation was observed, no reliable estimate can be made). Pairing by worm, the Friedman's test indicated no treatment difference ( $p=0.62)$. There is little difference in medians and a relatively high range of values, due probably to the differences in size among worms in the experimental population. In fact, the difference between the maxima can be attributed to the variability of 1 worm, namely $A$. No large difference in amount of material in the gut was seen as would be necessary where ingestion and egestion rates temporarily uncoupled (see Jumars \& Self 1986).

I conducted this experiment to test hypothetical mechanisms with the observed rates of increasing and decreasing feeding rates and gut throughput times. The results of this experiment led me to reject several of these mechanisms for the rate of response to step change in diet as described in the next section.

\section{DISCUSSION}

\section{Fecal material experiment}

My original hypothesis was that surface deposit feeders should respond rapidly to changes in sedimentary food resources available to them. The initial test of this hypothesis was made by feeding individual Saccoglossus kowalevskii their own fecal material and measuring their egestion rate. The choice of sediment treatments in this (and the following) experiments was extreme by design to elicit a large egestion rate effect. Analysis of the results clearly indicated that consumption of fecal material occurred more slowly than of fresh sediment, though the rate decrease was delayed ca $1 \mathrm{~h}$ and the magnitude varied through the experiment (Fig. 1, Table 1). If application of fecal material had immediately decreased egestion rate, this would have been evident in the first hour's data (Fig. 1, left-most or $+1 \mathrm{~h}$ pairs of bars), and is not an artifact of sampling design or frequency. If ingestion rate had responded rapidly, this too would have been seen unless there were a concomitant decrease in the volume of material in the gut (which is doubtful given results in Fig. $4 \mathrm{~B}$ discussed above). The increased variability in the last hour of the experiment (Fig. 1, +4 h), which rendered the large difference in means of all factors statistically non-significant, might well be due to complete consumption of the fresh sediment by this point in the experiment. As intended by the experimental protocol, the amount supplied was equivalent in wet weight to that egested before application. With a $14 \%$ increase in egestion rate for $+1 \mathrm{~h}$ to +3 $h$, the fresh sediment worms could then have consumed all the fresh sediment supplied, effectively ending the desired treatment effect. Worms would by then have been feeding on whatever sediment remained in their pit or was reachable by their proboscis. A related explanation also may account for the increase in variability seen in the fecal material group.

The decrease in egestion rate, but not its delay, could be predicted from Miller \& Jumars' (1986) similarly impolite experiments with assemblages of the surface deposit feeder Pseudopolydora kempi japonica. They found that the accumulation of feces in the feeding area surrounding the tube leads to depressed feeding rates. In this species, pellets are released above the bed and swept downstream of the feeding area in all but still water. Consequently, the effect of fecal pellets would be largely ameliorated in the field, though the degree is dependent on the areal abundance and spatial arrangement of worms. In Miller \& Jumars' laboratory experiments, pellets accumulated gradually as the worms egested them, and a slow decrease in egestion rate was noted (Fig. 4 in Miller \& Jumars 1986). Consequently, if $P$. kempi japonica exhibited any delayed response, it would have been almost impossible to detect in the experiment conducted.

In contrast, Saccoglossus kowalevskii feed and defecate in separate areas, so one would expect no such depression of feeding rate in still water experiments. None was seen in the present experiments (e.g. Fig. 2A, solid bars, left half). When collecting $S$. kowalevskii in the field, we often locate individuals by the presence of small, newly egested fecal coils. We have less frequently observed feeding pits in the field. These observations suggest that there is frequently sediment movement sufficient to fill feeding pits and to disrupt fecal material. K. Fielman \& E. Brandon (unpubl.) in an April 1990 survey at Cape Henlopen found typical abundances of S. kowalevskii of $10^{\prime}$ s to several $100 \mathrm{~s} \mathrm{~m}^{-2}$, a range encompassing abundances quoted by Carey \& Farrington (1989) for a Cape Cod, Massachusetts, USA, population. At $10 \mathrm{~m}^{-2}$, essentially equivalent to that abundance used in laboratory experiments, fecal piles occupy $<10 \%$ of the sediment surface in the seawater table 
with no natural sediment movement (pers. obs.). Even if this material was transported and uniformly distributed by wave action, it would be sufficiently diluted by surficial sediment that little fecal material would find its way into feeding areas (for measured rates, see Grant 1983, 1985, Miller \& Stermberg 1988; for speculation see Miller et al. 1984). Because of the somewhat low abundances of individuals at Cape Henlopen, it is unlikely that in all but the densest patches accumulation of fecal material depresses feeding rate, even in tidepools. This contrasts to the situation of Pseudopolydora kempi japonica (Miller \& Jumars 1986) where worm abundances are a factor of 100 or more higher. Although probably not a field-relevant effect (thus impertinent as well as insolent), the depression and delay in egestion rate attributed to fecal material seen in Fig. 1 did force me to reject the initial hypothesis of a rapid feeding response to changes in diet

It is well known that enteropneusts, including Saccoglossus kowalevskii (King 1986, 1988, Woodin et al. 1987), produce halogenated ring compounds and that these compounds are likely present in their feces (Higa \& Sakemi 1983, King 1986). Given the novelty of these compounds in the sediments, they could play a role in deposit-feeding as a label for recently egested material. Considering the above dilution argument, these compounds would act as a feces-rejection cue only if present in high enough concentrations to overcome sediment dilution (above) and elevated background levels near the worm itself. For the Cape Henlopen population of $S$. kowalevskii, C. Stoop and K. Fielman (pers. comm.) have found that 2,3,4-tribromopyrrole was present only in trace quantities in fecal material (as compared to the worm itself) and that breakdown of this compound to bromide was relatively rapid. However, I cannot completely discount the possibility that some chemosensory rejection of fecal material caused the observed depressed feeding rate. As intended by protocol, dilution of fecal material with fresh sediment did not occur in my experiment so that any such effects should be more apparent in these experiments than in the field. This effect would best be tested for by addition of the putative inhibitory compounds to fresh sediment and feeding to S. kowalevskil and other species not naturally producing or encountering such allelochemicals. In any case, it is doubtful that any such halogenated compounds were present in the glass beads used in subsequent experiments that elicited similar feeding responses.

\section{Glass bead experiment}

I tested the revised hypothesis that the egestion rate response would be delayed and gradual by feeding individuals with glass beads of no nutritional value. These data revealed (Fig. 2A) a gradual and delayed decrease in egestion rate that persisted over the $8 \mathrm{~h}$ duration of the experiment. After application of glass beads, worms quickly resumed exploration of the sediment with the proboscis and normal still-water, surface-deposit feeding behavior. The initial delay is not attributable to subsurface feeding since no dark feces were seen. There was always a clear demarcation between sand and glass bead containing feces, even within the same fecal strand. This supports the presumption that a step change in diet had occurred as intended. Following bead application, the decrease appeared to be exponential with a limiting value of about $250 \mathrm{mg} \mathrm{h}^{-1}$ worm $^{-1}$ (or about half of preapplication values) on glass beads of presumably little or no nutritional value. Over the $8 \mathrm{~h}$ period, mean egestion rate fell at a rate of $\left(44 \mathrm{mg} \mathrm{h}^{-1}\right) \mathrm{h}^{-1}$ as estimated by a linear least-squares approach. Although the treatment effects in this experiment are confounded with time, examination of the individual worm data indicates that this gradual decrease is not an artifact of aggregating data of individuals differing in their response (Fig. 2B). Temperature control was satisfactory $\left( \pm 0.2^{\circ} \mathrm{C}\right)$ and cannot explain the egestion rate differences observed.

The experimental design used in the glass bead and reciprocal experiments was a repeated-measures design with worms as subjects and repeated measurements of egesta mass at hourly intervals (Kirk 1982). In the partitioning of the sums of squares and formation of the F-ratios, this design is equivalent to the randomized complete blocks design with subjects considered as blocks (Montgomery 1984). Besides the standard ANOVA assumptions of independence of observations, randomness and normality of errors and equality of variances, the analysis of these designs assumes no interaction and certain symmetry characteristics of the variance-covariance matrix (Winer 1971, Kirk 1982, Milliken \& Johnson 1984). Interaction or nonadditivity would be most simply evident in these experiments as a difference in response among worms correlated with mean feeding rate, for example, decreasing egestion rate proportionately (say, by half) rather than some fixed amount (e.g. $250 \mathrm{mg} \mathrm{h}^{-1}$ ). The effect on F-tests of interest is a loss of power (Kirk 1982). As described above, for simplicity of analysis (Milliken \& Johnson 1989) and interpretation of slopes, I have used the analysis of untransformed data for the remaining experiments despite the potential loss of power.

In the conventional repeated measures designs, certain assumptions are placed on the variability in the experiment. A sufficient property, known as the symmetry condition (Winer 1971, Kirk 1982, Milliken \& Johnson 1984), is that the treatment variances be equal and that treatments be all equally correlated. Under 
conditions of varying feeding rate as used, variances across the hours may well differ (e.g. by being correlated with the means), and rates could be more highly correlated for consecutive hours than for periods farther apart. These conditions represent violation of the symmetry assumption. The effect is to bias positively the F-tests, causing too many significant results. Fortunately, there are readily available conservative and adjusted F-tests (Kirk 1982). For repeated measures experiments reported here, all treatment (hour) tests remain statistically significant when tested by the procedure of decreasing the degrees of freedom for the critical values. When tested by the single d.f. linear trends tests (Milliken \& Johnson 1984, 1989), all slopes likewise remain statistically significant. A more rigorous analysis of these points will be presented elsewhere (Miller unpubl.), though the results cited above indicate effects and slopes are still highly significant and violations do not vitiate the conclusions presented below

\section{Tests of hypothetical response mechanisms}

The full $1 \mathrm{~h}$ delay seen in the above experiments is about the same length as the 49 min median gut throughput time measured in the glass bead experiment. This observation suggests several possible mechanisms for the delay. First and most simply, the worm may adjust its feeding rate based on the digestive products and nutrition actually derived from the food assessed following digestion, at the distal region of the intestine or other region of absorption (for Saccoglossus kowalevskii, Russell-Hunter 1969). Here, the delay is caused by, and identical to, the gut throughput time. There should be a strong asymmetry in response to high vs low feeding rate foodstuffs: if throughput time is inversely related to feeding rate, the rise in feeding rate should be delayed and take longer than the fall. The mode of 'feedback' is not known (but see Knight-Jones 1952), but neural control is sufficiently fast that it would not cause appreciable delay itself. The same is probably true for hormonal control, though no mechanism has yet been demonstrated (Laverack \& Dando 1987). Irrespective of the means of control, this explanation for egestion rate response will be termed the hindgut-feedback hypothesis.

Another possible explanation for the delay and gradual change is that it results from changes in digestive physiology resulting from changes in diet. One would expect these changes to occur on time scales equal to or longer than the gut throughput time. The time scale would likely be a complex function of the food composition, amount and recent feeding and physiological history of the mechanisms considered, this is the most complex and least understood. Without more detailed understanding of relevant and important food components, digestive kinetics and physiological responses, it is difficult to predict more specifically how the delay, rate of response or gut throughput time will vary.

As no one has yet formulated a dynamic mathematical model for microphagous feeders (Jumars \& Penry 1989. Taghon 1989), I will speculate on how egestion rate should change in response to changes in diet. When switched from good food to poor, feeding rate should fall slowly; it is energetically advantageous to retain and more fully digest the more nutritious material. When newly provided with relatively good food on which faster feeding is energetically optimal, the change should be made quickly. No net energetic loss is suffered by flushing energy-poor material through the gut only to be replaced by better. Thus an optimal forager should respond quickly to increase feeding rate, and slowly to decrease feeding rate. This explanation predicts that a fall in feeding rate will occur more slowly than a rise and contrasts with the predictions above. Note that this argument has been made without reference to unspecified costs (Taghon 1988. Dade et al. 1990) of feeding or of changing feeding rate, though the key assumption is that food quality, rate of energy gain and feeding rate are all positively related. A more in-depth and less superficial application of dynamic principles to feeding (e.g. Clark 1976. Stephens \& Krebs 1986, Mangel \& Clark 1988) is certainly fertile ground for new modeling efforts (see discussion in Miller et al, in press). These problems also can be formalized in terms of optimizing the behavior of systems, known as optimal control theory (e.g. Eisen 1988). Here, the problem for the microphage is to change the feeding rate (or more generally, feeding behavior) to that appropriate for new conditions in such a way that maximizes the benefits and mimimizes risks and costs.

More complex hypotheses are possible. For example, deposition of particles, regardless of their nutritional content, may somehow stimulate feeding. The combined effect of a stimulated feeding activity and an otherwise decreased feeding rate on the new particles would lead to an apparent, temporary delay. There is some evidence for such stimulation in the initial experiments: the increased egestion rate for the fresh sediment group in Fig. 1 and similar increase from $-8 \mathrm{~h}$ to $-6 \mathrm{~h}$ in Fig. 2A following application of fresh sediment at the start of the glass bead experiment. The joint effect could result in a rate not different from that before deposition. One would, however, expect to see no delay when feeding rate is increasing since the 2 effects would act in the same direction. Thus by comparing delays under decreasing and increasing feeding 
conditions, this hypothesis can be distinguished from the others proposed. Higher-order interactions of behavior (e.g. withdrawal; Levinton 1991, Miller et al. in press) and egestion rate (above) could lead to simple appearing responses that are based on complicated underlying mechanisms.

Last, and for completeness, I will consider a null model. Here, if the rate of response does not vary, there is no asymmetry in response from high to low feeding rates. Paradoxically, this mechanism implies either that there is no advantage to altering response or that no differential response is the optimal one. Symmetrical response to steps changes in diet and feeding rate may be an adaptation that averages or smooths over environmental variations on the minutes-hours time scale. Perhaps there is no advantage and perhaps significant costs are associated with rapid changes in feeding rate. This comment applies particularly to worms like Saccoglossus kowalevskii (among others, arenicolids, Cadée 1976, Taghon 1988; and some earthworms, Voisin 1961) that process unselectively relatively large amounts of sediment. There are numerous other options for a response to changing diet, including depth and lateral location of feeding.

These hypotheses concerning the mechanism for the delayed, gradual response were tested with the reciprocal experiment (Figs, $3 \& 4$, Table 3 ). The rate of decrease in egestion rate (fresh sediment to glass beads) was significantly slower than the rate of increase in egestion rate (Fig. 3, Table 3) using the $t$-test with conventional error terms and degrees of freedom. Test probabilities are reported as 2 -tailed since differences in either direction were possible under the hypotheses discussed above. Gut throughput times were significantly shorter on the fall than on the rise (Fig. 4A). Clearly, the null hypothesis and model are rejected. The result of at least this experiment was that the observed delay was longer on the fall (ca 3 h vs 1 h; Fig. 3) and is much longer than the median throughput time ( $70 \mathrm{~min}$ ). This is not consistent with the hindgut-feedback hypothesis nor its prediction concerning relative rates Therefore, results indicate rejection of the hindgut feedback hypothesis. The presence of a $1 \mathrm{~h}$ delay on the rise (Fig. 3) leads me to reject the stimulated feeding mechanism. I accept provisionally the adapting digestive physiology hypotheses since delays were (in 1 case) longer, not shorter, than the throughput times. A firmer decision to accept or reject this hypothesis and more parsimonious interpretation of these results awaits better a priori prediction of experimental results and quite possibly new experimental methods. The relative rate results are most consistent with the general predictions of the dynamic foraging hypothesis, although the delay appears longer than the gut throughput time for decreasing feeding rate in this last experiment.

\section{Generalization and implications of results}

Saccoglossus kowalevskii clearly responds to step changes in diet in a delayed (Fig. 1, Table 1), gradual (Fig. 2, Table 2) and asymmetrical manner (Figs. 3 \& 4 , Table 3). Given the diversity of responses to flow and sediment flux even among deposit feeders (Nowell et al. 1989, Levinton 1991, Turner \& Miller 1991a, Miller et al. in press), it is risky to generalize these results blindly. Responses may differ among functional groups (Fauchald \& Jumars 1979), with subsurface deposit feeders (Miller et al. 1984) and others that process relatively large quantities of sediment less responsive. The characteristics of the response may be body-size dependent or related to weight-specific metabolic rates. The methods used above could also be combined with adjustment of temperature as another experimental factor to test this assertion. Gravimetric methods employed above could be used with macrofauna much smaller than $S$. kowalevskii by using higher-precision mass measurements. In conducting experiments at varying temperatures and with other species, it would be prudent to reentertain the hypotheses rejected for $S$. kowalevskii. Though more sophisticated methods are necessary to measure gut throughput time in worms with mixing chambers (Penry 1989, Penry \& Jumars 1990), it would be interesting to see if egestion rate responses are related to particle transport characteristics of the gut.

Although the response mechanism has not been determined precisely, the classical studies of KnightJones on the nervous system (1952) and feeding behavior (1953) of Saccoglossus kowalevskii suggest additional experimental approaches. Knight-Jones (1952) concluded that autonomous nervous activity was centered in the proboscis. Incision studies demonstrated the burrowing actions of the proboscis are under control of the nervous system. It seems likely to conclude that its feeding activities may be under nervous control as well. Histological studies and the arrangement of nerve plexus and bundles suggest that the proboscis and the pre-oral ciliary organ are capable of chemoreception. Both contact sediment particles in the normal depositfeeding process (Knight-Jones 1953). Stimuli received by this organ or the proboscis are probably integrated in and through the dorsal and ventral nerve tracts of the trunk region. They likely influence the muscular activity of the esophagus and possibly the ciliary activity of the intestine responsible for defecation. Nervous control of cilia has been demonstrated at other regions of the worm (e.g. gills and proboscis; Laverack \& Dando 1979). Knight-Jones (1952, p. 327), however, concluded that the cilia of the esophagus, hepatic region and intestine were not under nervous control. Retraction of the proboscis in feeding or of the distal end of the trunk (during defecation) can be rapid, and feeding and defecation 
can occur simultaneously (L. Shoda \& D. Brandon pers. comm.). Overall integration must necessarily be at a relatively simple level since there is no functional or structural evidence of major integrative activities (Russell-Hunter 1969). There are no obvious eyes or other highly organized sense organs. Additional observations and simple experiments should more clearly reveal the means by which feeding and defecation activities are coordinated.

The delayed, gradual response exhibited in egestion rate raises the issue of what other feeding variables, if any, respond slowly and on what time scales. Perhaps the best studied feature of deposit feeders, particle selection, is an obvious choice. It would be possible to conduct such a study using counting (e.g. Jumars et al. 1982, Miller 1984, Self \& Jumars 1988) or dry-sieving particle size techniques (Brandon 1991). Saccoglossus kowalevskii show little particle size selectivity and would not be a suitable candidate for such a study. Application of innovative physiological and biochemical techniques to measure digestive kinetic parameters (e.g. 'everted sleeve' method of Karasov \& Diamond 1983) could support or help reject physiological hypotheses proposed above. Additional evidence could come from studies of the histological changes in the hepatic, presumably secretory, region of the trunk (Russell-Hunter 1969) in S. kowalevskii

The observed response is not comparable with any existing microphage foraging model. All models that have been developed and tested, whether based on energetic (e.g. Taghon 1981) or digestive rate considerations (e.g. Dade et al. 1990), are steady-state. At best. these models can only predict that changes in egestion rate may occur with changes in diet over long periods. Even the direction of change, that is, the slope of the relevant region of the functional response curve, is not always certain (Taghon 1981; cf. Dade et al. 1990, Brandon 1991). These models cannot predict or explain why there should be a delay or how long it should be. I have argued here that a dynamic generalization of optimal foraging principles predicts that changes are made to maximize benefits. It should be more advantageous to change quickly to better conditions, more slowly to poorer. This is the basis for the predictions made for the reciprocal experiment, and those predictions were the most consistent with the experimental results. Unfortunately the present state of microphage modeling sheds little additional light on the mechanism or energetic rationale for such a response. It is not even evident that rapid responses have long-term selective advantages. There is a clear need for consideration of feeding dynamics in the physicists' sense (i.e., forces or causes of responses) in addition to feeding kinetics (rates and efficiencies only, apart from energetic and fitness considerations).
The delay in response to a step change in diet represents a decoupling of feeding and sediment food resources and dynamics on time scales of minutes to hours. Perhaps there is no selective advantage accrued via digestion for the rapid responses seen in feeding behavior (e.g. Nowell et al. 1989, Levinton 1991, Turner \& Miller 1991a, Miller et al. in press). Perhaps flow and sediment flux regimes typically used in the laboratory (Nowell et al. 1990, Levinton 1991, Turner \& Miller 1991a, Miller et al. in press) are too short and artificial to be realistic. The dominant time scale of change in flow and sediment flux in the field is hours to days (Miller \& Sternberg 1988, M. J. Bock unpubl.) and thus the discrepancy in time scales of response may be more apparent than real. The difference in time scale may merely reflect the means of integration, neural or hormonal, controlling the response.

The practical implication of the short-term decoupling of feeding rate and diet is that the marker or tracer methods used to measure ingestion rate (Jumars \& Self 1986, Carey 1989) may be reliable. Carey (1989) provides experimental verification of this statement with Saccoglossus kowalevskii. This is true even if the tracer, or more commonly, feeding marker, is applied in poorly controlled quantities that would by itself eventually change long-term feeding rates. This method is extremely valuable since it is one of the few that can be used in dynamic, sediment transporting environments where feces cannot be collected quantitatively. As with any newly applied technique, one must verify its reliability using standard measurements (e.g. gravimetric methods). If the delayed response proves to be widespread among deposit and suspension feeders, the applicability of the marker methods will have been significantly widened.

\section{CONCLUSIONS}

Laboratory experiments show that the surfacedeposit feeding enteropneust Saccoglossus kowalevskii responds slowly to rapid changes in diet. The delayed response is inconsistent with several proposed explanations, including some manner of feedback from the distal region of the gut, adaptation of digestive physiology, temporary stimulation of feeding activity and the null hypothesis of no difference in response to various foodstuffs. Of the alternatives examined, experimental results were most consistent with that derived from a dynamic optimal-foraging argument. Regardless of the explanation, the delay represents a decoupling of feeding and sediment food resources and dynamics on time scales of minutes to hours. Methods that use gut tracers or markers thus may be reliable measures of short term feeding rates. 
Acknowledgements. I thank E. Brandon, R. Kirschner, A. Ray, L. Shoda and B. Turner for help in collecting and maintaining experimental animals. M. Bock, L. Karrh, D. Penry and R. Raborg and 3 reviewers offered intriguing and valuable comments on this manuscript. K. Fielman provided interesting discussions and access to unpublished results bearing on fate of tribromopyrrole in local sediments. This research was supported by National Science Foundation Biological Oceanography Program Grants OCE 87-10768 and 89-11447

\section{LITERATURE CITED}

Agassiz, A. (1873). The history of Balanoglossus and Tornaria Mem. Amer Acad. Arts Sci. 9: 421-436

Bianchi, T S. (1988). Feeding ecology of subsurface depositfeeder Leitoscoloplos fragilis Verrill. I. Mechanisms affecting particle availability on an intertidal sandflat. J. exp. mar. Biol. Ecol. 115: 79-97

Brandon, E. A. A. (1991). Interactions of Saccoglossus, sediment, and microalgae: theory and experiment. M.Sc thesis, University of Delaware, Newark

Cadée, G. C. (1976). Sediment reworking by Arenicola marina on tidal flats in the Dutch Wadden Sea. Neth. J. Sea. Res. 10: $440-460$

Carey, D. A. (1989). Fluorometric detection of tracer particles used to study animal-particle dynamics. Limnol. Oceanogr. 34: 630-635

Carey, D. A., Farrington, J. W (1989). Polycyclic aromatic hydrocarbons in Saccoglossus kowalevskii (Agassiz). Estuar coast. Shelf Sci. 29: 97-113

Carey, D. A., Mayer, L. M. (1990). Nutrient uptake by a deposit-feeding enteropneust: nitrogenous sources. Mar. Ecol. Prog. Ser. 63: 79-84

Clark, C. W (1976). Mathematical bioeconomics. John Wiley \& Sons, New York

Dade, W B., Jumars, P. A., Penry, D. L. (1990). Supply-side optimization: maximizing absorptive rates. In: Hughes, R. N. (ed.) Behavioural mechanisms of food selection. NATO ASI Ser. (G: Ecol. Sciences) Vol. 20. SpringerVerlag, Berlin, p. 531-556

Dobbs, F. C., Guckert, J. B. (1988), Microbial food resources of the macrofaunal-deposit-feeder Ptychodera bahamensis (Hemichordata: Enteropneusta). Mar Ecol. Prog. Ser. 45: $127-136$

Eisen, M. (1988). Mathematical methods and models in the biological sciences. Prentice-Hall, Englewood Cliffs

Fauchald, K., Jumars, P. A. (1979). The diet of worms: a study of polychaete feeding guilds. Oceanogr. mar. Biol. A. Rev. 17. $193-284$

Grant, J. (1983). The relative magnitude of biological and physical sediment reworking in an intertidal community. J mar. Res. 41: 673-689

Grant, J. (1985). A method for measuring horizontal transport of organic carbon over sediments. Can. J. Fish. Aquat. Sci 42: 595-602

Higa, T., Sakemi, S.-I. (1983). Environmental studies on natural halogen compounds. I. Estimation of biomass of the acorn worm Ptychodera flava Eschscholtz (Hemichordata: Enteropneusta) and excretion rate of metabolites at Kattore Bay, Kohama Island, Okinawa. J. chem. Ecol. 9: 495-502

Hyman, L. H. (1959). The invertebrates, Vol. 5. McGraw-Hill, New York

Jumars, P. A., Penry, D. L. (1989). Digestion theory applied to deposit feeding. In: Lopez, G., Taghon, G., Levinton, J. (eds.) Ecology of marine deposit feeders. Springer-Verlag, New York, p. 114-128
Jumars, P. A., Self, R. F. L. (1986). Gut-marker and gutfullness methods for estimating field and laboratory effects of sediment transport on ingestion rates of deposit feeders. J. exp. mar. Biol. Ecol. 98: 293-310

Jumars, P. A., Self, R. F. L., Nowell, A. R. M. (1982). Mechanics of particle selection by tentaculate deposit feeders. J. exp. mar Biol. Ecol. 64: 47-70

Karasov, W. H., Diamond, J. M. (1983). A simple method for measuring intestinal solute uptake in vitro. J. comp. Physiol. 152: 105-116

King, G. M. (1986). Inhibition of microbial activity in marine sediments by a bromophenol from a hemichordate. Nature 323: $257-259$

King, G. M. (1988). Dehalogenation in marine sediments containing natural sources of halophenols. Appl. environ. Microbiol. 54: 3079-3085

Kirk, R. E. (1982). Experimental design: procedures for the behavioral sciences, 2nd edn. Brooks/Cole, Belmont

Knight-Jones, E. W. (1952). On the nervous system of Saccoglossus cambrensis (Enteropneusta). Phil. Trans. R. Soc. (Ser. B) 236: 315-354

Knight-Jones, E. W. (1953). Feeding in Saccoglossus (Enteropneustal. Proc. zool. Soc. Lond. 123: 637-654

Laverack, M. S., Dando, J. (1987). Lecture notes on invertebrate zoology, 3rd edn. Blackwell Scientific, Oxford

Levinton, J. S. (1991). Variable feeding behavior in three species of Macoma (Bivalvia: Tellinacea) as a response to water flow and sediment transport. Mar. Biol. 110: 375-383

Mangel, M., Clark, C. W (1988). Dynamic modeling in behavioral ecology. Princeton University Press, Princeton

Maurer, D., Aprill, G. (1979). Intertidal benthic invertebrates and sediment stability at the mouth of Delaware Bay. Int. Revue ges. Hydrobiol. 64: 379-403

Mayer, L. M., Rice, D. L. (1992). Early diagenesis of protein: a seasonal study. Limnol. Oceanogr. 37: 280-295

Mayer, L. M., Schick, L. L., Setchell, F. W. (1986). Measurement of protein in nearshore marine sediments. Mar. Ecol. Prog. Ser. 30: 159-165

Miller, D. C. (1984). Mechanical post-capture particle selection by suspension- and deposit-feeding Corophium. J. exp. mar. Biol. Ecol. 82: 59-76

Miller, D. C., Bock, M. J., Turner, E. J. (in press). Deposit and suspension feeding in oscillatory flows and sediment fluxes. J. mar. Res.

Miller, D. C., Jumars, P. A. (1986). Pellet accumulation, sediment supply, and crowding as determinants of surface deposit-feeding rate in Pseudopolydora kempi japonica Imajima \& Hartman (Polychaeta: Spionidae). J. exp. mar. Biol. Ecol. 99: 1-17

Miller, D. C., Jumars, P. A., Nowell, A. R. M. (1984). Effects of sediment transport on deposit feeding: scaling arguments. Limnol. Oceanogr. 29: 1202-1217

Miller, D. C., Sternberg, R. W. (1988). Field measurements of the fluid and sediment-dynamic environment of a benthic deposit feeder. J. mar. Res. 46: 771-796

Milliken, G. A., Johnson, D. E. (1984). Analysis of messy data. Vol. 1. Designed experiments. Van Nostrand Reinhold, New York

Milliken, G. A., Johnson, D. E. (1989). Analysis of messy data. Vol. 2. Nonreplicated experiments. Van Nostrand Reinhold, New York

Montgomery, D. C. (1984). Design and analysis of experiments. 2nd edn. Wiley, New York

Nowell, A. R. M., Jumars, P. A., Self, R. F. L., Southard, J. B. (1989). The effects of sediment transport and deposition on infauna: results obtained in a specially designed flume. In: Lopez, G., Taghon, G. L., Levinton, J. S. (eds.) Ecology of 
marine deposit feeders. Springer-Verlag, New York, p $247-268$

Penry, D. L. (1989). Tests of kinematic models for deposit feeders guts: patterns of sediment processing by Parastichopus califorinicus (Stimpson) and Amphicteis scaphobranchiata Moore (Polychaeta). J. exp. mar. Biol. Ecol. 128: 127-146

Penry, D. L., Jumars, P. A. (1987). Modeling animal guts as chemical reactors. Am. Nat. 129:69-96

Penry, D. L., Jumars, P. A. (1990). Gut architecture, digestive constraints and feeding ecology of deposit-feeding and carnivorous polychaetes. Oecologia $82: 1-11$

Ray, A. J. (1989). Influence of sediment dynamics and deposit feeding on benthic microalgae. M.Sc. thesis, University of Delaware, College of Marine Studies, Newark

Ruppert, E., Fox, R. (1988). Seashore animals of the Southeast. Univ. South Carolina Press, Columbia

Russell-Hunter, W. D. (1969). A biology of higher invertebrates. Macmillan, London

Self, R. F. L., Jumars, P. A. (1988). Cross-phyletic patterns of particle selection by deposit feeders. J. mar. Res. 46 : 119-143

Shimeta, J., Jumars, P. A. (1991). Physical mechanisms and rates of particle capture by suspension feeders. Oceanogr. mar. Biol. A. Rev. 29: 191-257

Stephens, D. W., Krebs, J. R. (1986). Foraging theory. Princeton University Press, Princeton

Taghon, G. L. (1981). Beyond selection: optimal ingestion rate as a function of food quality. Am. Nat. 118: 202-214

Taghon, G. L. (1988). The benefits and costs of deposit feeding

This article was presented by K. R. Tenore, Solomons, Maryland, USA in the polychaete Abarenicola pacifica. Limnol. Oceanogr. 33: 1166-1175

Taghon, G. L. (1989). Modeling deposit feeding. In: Lopez, G., Taghon, G. L., Levinton, J. S. (eds.) Ecology of marine deposit feeders. Springer-Verlag, New York, p. 223-246

Taghon, G. L., Greene, R. R. (1990). Effects of sedimentprotein concentration on feeding and growth rates of Abarenicola pacifica Healy et Wells (Polychaeta: Arenicolidae). J. exp. mar. Biol. Ecol. 136: 197-216

Taghon, G. L., Greene, R. R. (in press). Utilization of deposited and suspended particulate matter by benthic 'interface' feeders Limnol. Oceanogr.

Trager, G. C., Hwang, J.-S., Strickler, J. R. (1990). Barnacle suspension-feeding in variable flow. Mar. Biol. 105: 117-127

Turner, E. J., Miller, D. C. (1991a). Behavior of a passive suspension-feeder [Spiochaetopterus oculatus (Webster)] under oscillatory flow. J. exp. mar. Biol. Ecol. 149: 123-137

Turner, E. J., Miller, D. C. (1991b). Behavior and growth of Mercenaria mercenaria during simulated storm events. Mar Biol. 111: 55-64

Voisin, A. (1961). Lazy and active earthworms. In: Rodale, R. (ed.) The challenge of earthworm research. Soil and Health Foundation, Emmaus, PA, p. 9-13

Winer, B. J. (1971). Statistical principles in experimental design. 2nd edn. McGraw-Hill, New York

Woodin, S. A., Walla, M. D., Lincoln, D. E. (1987). Occurrence of brominated compounds in soft-bottom benthic organisms. J. exp. mar. Biol. Ecol. 107: 209-217

Zar, J. H. (1984). Biostatistical analysis. 2nd edn. PrenticeHall, Englewood Cliffs

Manuscript first received: December 19, 1991

Revised version accepted: August 17, 1992 